\title{
Las estructuras de sentido de la vida cotidiana
}

\author{
Faustino M iguélez \\ Teresa Torns \\ O scar Rebollo \\ Inma Pastor \\ Universitat Autònoma de Barcelona. D epartament de Sociologia \\ 08193 Bellaterra (Barcelona). Spain
}

\section{Resumen}

Una vez examinadas las relaciones en el nivel de las actividades objetivables entre ámbitos y en el de las representaciones y actitudes, parece lógico y consecuente que se realice un paso posterior: ¿cómo las personas, situadas en posiciones características dentro de las tipologías precedentes de articulación entre ámbitos, construyen un espacio intencional, de sentido y/o simbólico tomando como referencia de contenidos dichos ámbitos y sus vinculaciones? ¿Cómo se forman lo que denominamos «estructuras u orientaciones de sentido»? Es decir, ¿cómo se organiza el mundo de sus deseos, de sus aspiraciones y de sus proyectos en función de las centralidades que cada ámbito tiene según momentos del día y épocas de la vida? Evidentemente, para obtener información de cara a este objetivo hemos tenido que retornar de nuevo a los entrevistados y, por medio de entrevistas semidirigidas, indagar y reconstruir en el análisis este mundo simbólico.

Este artículo es parte de una investigación cuyos resultados aparecen en este mismo número de PAPERS. El artículo tiene autonomía y entidad por sí mismo pero la lectura del resto de los artículos de este número facilitará su contextualización.

Palabras clave: orientaciones simbólicas, proyectos y aspiraciones, tiempo cotidiano, tiempo de vida, entrevistas en profundidad.

\section{Abstract}

After examining the relations between areas at the level of the objectifiable activities and at the level of representations and attitudes, it seems logical and consequent to take a further step: how do people, located in characteristic positions inside the previous typologies of articulation among environments, build a meaningful or symbolic intentional space by taking these areas and the links between them as a reference of content? $\mathrm{H}$ ow are what we call structures or orientations of meaning formed? That is to say, how is the world of their desires, their aspirations and their projects organised on the basis of the centralities that each environment has according to the time of day and the time of life? Evidently, to obtain information for this objective we had to return to the interviewees and investigate and reconstruct this symbolic world through semi-directed interviews.

This paper is part of a research work whose results are in this PAPERS volume. The paper is autonomous but the reading of the other papers of this volum can help to contextual ize it.

Key words: simbolic orientations, projects and aspirations, time of day, time of life, depth interviews. 


\section{Sumario}

1. Introducción

2. La centralidad de la vida cotidiana: coherencias e incoherencias
3. Las trayectórias biográficas como corriente de fondo de la vida cotidiana

4. Vida cotidiana y cambio: las transiciones

\section{Introducción}

\subsection{Aspectos generales}

En este artículo entramos en la exploración de lo que hemos denominado «estructuras de sentido de la vida cotidiana», y no en abstracto, sino en referencia al contexto social en que vivimos: en un país de notable desarrollo económico, de un alto grado de especialización, de fuertes divisiones y desigualdades y donde lo individual adquiere una importancia creciente. Tal como señalábamos en la introducción de este volumen, la preocupación por el análisis de la vida cotidiana de las personas nace de una doble limitación de los análisis tradicionales de los fenómenos sociales: primero, porque tienden a trocear - y en parte a desfigurar - lo social, refiriéndose, por un lado, a la familia y, por otro, al trabajo o a la educación o a la política, a pesar de que las personas que están en unos u otros ámbitos o en los grupos, organizaciones e instituciones que los animan, pueden ser las mismas; y segundo, porque los análisis tienden, frecuentemente, a captar lo pautado, formalizado y normatizado, dejando en la sombra la savia y los flujos «débiles» que los unen a través de las personas, que son las que real izan el vínculo.

Sin embargo, no cabe caer ni en un subjetivismo individualista ni, evidentemente, en el biologismo: las vidas cotidianas de hombres y mujeres no están marcadas en sus AD N ni son el resultado de opciones abstractamente libres; por el contrario, están fuertemente, aunque no determinantemente, marcadas por las estructuras sociales en las que se mueven. D ichas estructuras sociales, en un mundo como el nuestro, se hallan a su vez grandemente condicionadas por las formas en las que se producen y distribuyen los bienes y recursos materiales sin los que hombres y mujeres no sólo no tendrían las condiciones de vida y consumo, sino ni siquiera vivirían y, por supuesto, tampoco tendrían otros valores. En este sentido, nuestro punto de vista, por tanto, se acerca más a una visión materialista, no idealista, pero sin dejar de lado el importante peso que las percepciones, intenciones, proyectos, etc., en suma, la construcción simbólica de la persona, tiene en la acción social y en la misma constitución de las estructuras e instituciones sociales. El análisis de todo esto es precisamente el contenido de este artículo.

También hemos pretendido sistematizar - ha sido la segunda fase de la investigación- , a través de una tipología adecuada, las actitudes y percepciones de la gente ante diversos aspectos de la vida cotidiana; con ello queríamos llegar a los procesos de socialización que están en la base de la misma, es decir, desentrañar la importancia que para la gente tienen pautas y valores del tra- 
bajo productivo, del trabajo reproductivo y del tiempo libre. Dicho con otras palabras, que finalmente las vidas cotidianas de la gente discurran por unos u otros derroteros tiene que ver con las estructuras sociales en las que se hallan, pero también con los valores, las ideas y los ideales en los que han sido y son educados y reeducados.

Al hablar ahora de las estructuras u orientaciones de sentido de la vida cotidiana, como culminación en profundidad e intensidad de la investigación, nos referimos a las construcciones y elaboraciones simbólicas de los individuos que son el resultado de apropiaciones, representaciones, interpretaciones, procesos intencionales o imaginarios y relaciones instrumento/fin, que dan significación, legitiman o racionalizan, desde la perspectiva del actor, su actuación en el mundo. Son estructuras, ya que se trata de construcciones más o menos articuladas, más o menos coherentes e hilvanadas, constituyendo entidades simbólicas con un determinado grado de autonomía y clausura interna. Estos «universos» de estructuras de sentido dan, por un lado, significación; esto es, hacen no arbitraria nuestra actuación pasada, presente y futura y su propia concatenación temporal. Las perspectivas constructivistas, en general, hacen de éste el único mundo real sociológicamente hablando y su comprensión, la única posibilidad metodológica para explicarlo. $\mathrm{H}$ emos concebido nuestra posición, de base más materialista, al go más dual. Tal como hemos insistido, dichas orientaciones no son ajenas o independientes de las constricciones que sobre ellas ejerce la estructura social, pero también poseen unos márgenes de apertura y de indeterminación propios de la libertad.

Las estructuras de sentido tienen diversos niveles o componentes de identidad y orientación de la acción:

1) El primer nivel de estos componentes está básicamente configurado por lo que denominamos «val ores simbólicos» en tanto que contenidos, percibidos, representados e interpretados por el individuo como objetos de deseo, como beneficios satisfactorios obtenibles por su potencial o real apropiación, en tanto que recursos. Son elementos que forman parte de nuestras estrategias de acción, sean de solidaridad, sean de intercambio. Son, de esta manera, los «lugares» donde previsiblemente se colocará «nuestro corazón» y señalan qué tipo de satisfacción procuran, sea económica, de prestigio, de poder, etc. Se trata de analizar cómo los valores vinculados al trabajo productivo, reproductivo o disponibilidad de tiempo libre son percibidos, representados e interpretados como objetos de «apetencia» y cuya apropiación por parte de los actores sociales es fuente de satisfacción. D e hecho, se trata de examinar la centralidad de cada uno de los ámbitos considerados a partir del grado y la naturaleza de la satisfacción que procuran en sí mismos y de un ámbito con relación a otro.

2) El segundo nivel o dimensión consiste en procesos y contenidos simbólicos: se trata de procesos y contenidos que son transferencias, proyecciones 0 hipóstasis que realiza el actor social de una realidad, real o imaginada, sobre otra realidad (aquí la del trabajo productivo, reproductivo o tiempo libre), 
ya sea en el presente, en el pasado o en el futuro. Es una transmutación 0 cambio de identidad objetiva o virtual (por ejemplo, en forma ideológica), real o posible. Su soporte son, como todas las estructuras de sentido, representaciones, memorias, procesos intencionales, desarrollos discursivos y contenidos elaborados individual o colectivamente. En este nivel orientamos nuestra pesquisa a analizar hasta qué punto cada uno de estos ámbitos (actividad laboral, dedicación al hogar y la familia y tiempo libre), constituyen un discurso o elementos del mismo por el que se interpretan reflexiva o transitivamente unos ámbitos a partir de otros: así, por ejemplo, podemos hablar de unos contenidos simbólicos productivistas, en la medida en que bajo su prisma son leídos, interpretados, identificados e ideológicamente justificados los otros ámbitos. Ídem para los reproductivistas o de tiempo libre. Se trata de una centralidad de tipo interpretativa e identificativa simbólicamente de unos ámbitos a partir de otros.

3) El tercer elemento o dimensión lo hemos denominado ethos en tanto que criterios de relación entre medio/fin en la orientación y realización de una actividad por unos individuos. Concretamente, en nuestro caso, investigamos hasta qué punto uno u otro de los ámbitos es utilizado como instrumento, soporte, mediación o finalidad para o en la realización de otro; es decir, cuál es y cómo se realiza la estrategia de relación de unos ámbitos con otros y el grado de consciencia y responsabilidad con que se asume la vinculación y el equilibrio entre ellos. Se trata también de un análisis de la centralidad vía relación medio/fin.

A partir de las tres componentes, lo básico de nuestra investigación en esta tercera fase consiste en el análisis de la centralidad de cada uno de los ámbitos bajo esta triple perspectiva:

1) bajo el prisma de los valores simbólicos en forma de satisfacción, procurada por los beneficios obtenibles por la apropiación vía satisfacción, producida por valores económicos, de prestigio, de poder, etc.;

2) bajo la visión de unos contenidos simbólicos obtenidos por el peso que cada ámbito tiene en la representación, legitimación e identificación de los otros, y

3) una expresión ética en el sentido de la relación instrumental/finalidad que un ámbito tiene con relación a los otros.

$M$ anteniendo los tres ámbitos materiales de presencia que hemos tenido en cuenta a lo largo de toda la investigación - el trabajo productivo, el trabajo reproductivo y el tiempo libre- , el espacio de análisis de las estructuras de sentido de la vida cotidiana no puede basarse sino en la historia particular de cada cual, que, por supuesto, está imbricada necesariamente en la historia colectiva. N o es posible hablar de las orientaciones, sin referirse a su despliegue en el tiempo: esas orientaciones tienen un presente, que en gran parte es hijo del pasado y padre del futuro; se tiene una determinada orientación hoy, en 
parte porque se estuvo orientado en el pasado de cierta manera y lo que pase en el futuro - que la gente desea prefigurar de una u otra manera y no dejarlo a un ciego destino- depende mucho de lo que se está haciendo y valorando en el presente. Un nivel de temporalidad más microscópico es considerado también para cada uno. Ésta es la principal razón por la cual la recogida de datos en esta tercera fase ha privilegiado la entrevista biográfica.

\section{2. «M odelos» de vida cotidiana. M odelos puros y modelos en transición}

En un extremo tenemos al self-made man o la self-made woman, cuyas vidas cotidianas son - se entiende, desde que dan algún paso decisivo de autonomía - en gran parte producto de sus planes, de sus decisiones, de la lucha por los objetivos que se han propuesto, en los tres ámbitos que hemos contemplado. Tenemos, por otro, la persona cuya vida cotidiana aparece dictada por el destino, el fatalismo o algo semejante, aceptada y vivida de esa manera, siguiendo un curso natural que parece que la persona no puede cambiar. Son los dos extremos, que ciertamente no existen en toda su pureza, pero que pueden ser analíticamente descritos como tales, en tanto que tipos ideales, para mejor comprender las diferencias que hay en los estilos de vida cotidiana. En medio podemos encontrar diversos tipos, siguiendo, de todos modos, el eje que nos parece fundamental de autonomía versus heteronomía; también encontraremos una diversidad proveniente de la unidimensionalidad o pluridimensionalidad del modelo respecto a su contenido. D e manera que los cambios, que es el punto de vista que más puede interesar a la sociología, se pueden hipotizar desde el contenido (modelo puro versus modelo en transición o plural) o bien desde la forma en que se vive (heteronomía versus autonomía, de mayor a menor constricción).

Q uisiéramos insistir en el tema que nos parece clave desde la perspectiva del análisis de las estructuras de sentido de la vida cotidiana: el cambio en el modelo. Para ello utilizamos el concepto de transición, que se da tanto de un modelo a otro como de un modelo unidimensional a uno pluridimensional. N uestra hipótesis es que la vida cotidiana en el pasado estaba mucho más marcada por la unidimensionalidad, mientras que ahora se desarrollan tendencias pluridimensionales, debido a una serie de factores que iremos viendo, lo que puede dar origen a vidas cotidianas más complejas, al tiempo que potencialmente más equilibradas entre los géneros y las edades. En consecuencia, es exigible el diseño de nuevas políticas y hasta de un nuevo modelo de sociedad del bienestar, más basado en la calidad de vida y uso del tiempo que en la acumulación de bienes y servicios. Este nuevo modelo de vida cotidiana no tendrá necesariamente su epicentro en la producción y el trabajo profesión exclusivamente, sino en el uso y en la distribución de otros tiempos, en el equilibrio de las relaciones entre la natural eza y el trabajo y en las relaciones equilibradas entre los géneros.

Con el paso que ahora damos se trata de tener en cuenta el contexto y el tiempo históricos: no son idénticas las posibilidades de transición ahora que 
hace treinta años, en un contexto de crisis que en otro de auge y optimismo. Para captar esto hemos recurrido, precisamente, al análisis de biografías, lo que nos permite ver las trayectorias de la vida cotidiana y comprender mejor en qué momentos las transiciones se han desarrollan y por qué razones. Pero veamos primeramente estos model os puros y sus posibles transiciones.

\section{a) M odelo de centralidad en el trabajo productivo}

Se trata de una forma de vivir la vida cotidiana en la que el trabajo productivo es lo más importante para la persona. El trabajo reproductivo (casa y familia) y el tiempo libre tienen sentido sólo subordinadamente al productivo. Ello se simboliza en la importancia y el prestigio que se atribuye a la profesión en la propia vida. Aunque se diga que «o más importante es la familia», la profesión - para la que de hecho se vive- es del individuo, no de la familia. Trabajar fuera de casa puede dar una posición preeminente en el grupo doméstico, en los amigos y en las relaciones, los cuales están también fuertemente condicionados por el trabajo, la profesión, la afinidad de conocimientos y preocupaciones de esta índole. Lo mismo se puede decir, en el caso de que la hubiera, de la proyeccción publica como asociarse, afiliarse, militar políticamente.

Ciertamente que la centralidad productiva adquirirá unas u otras formas según el estrato laboral (segmentación) en el que la persona esté, pero también según otros factores tales como edad, género, categoría social y educación; tenemos bastantes indicios de fases anteriores de la investigación para sostener esta posición. Pero sobre todo está claro que la centralidad laboral es típicamente masculina.

Por ello las variaciones o transiciones en dicha centralidad pueden darse en varias direcciones. En primer lugar, en la dirección del sujeto, por ejemplo, el modelo puede ser asumido también por mujeres con la repercusión consiguiente sobre otras centralidades tradicional mente vividas por mujeres. En segundo lugar, en la dirección del contenido abriendo el paso a la centralidad bipolar o tripolar. Suponiendo que esa bipolaridad o tripolaridad equival ga a una vida cotidiana más compleja, quizá más equilibrada y equilibradora y menos generadora de desigualdades entre las personas que tienen relaciones habituales o forman parte de un mismo grupo de convivencia, los factores de la transición del modelo puro al modelo plural son de gran importancia para entender o prever cambios sociales de pequeña importancia aunque sea al nivel micro de la vida cotidiana. En tercer lugar, en la dirección de una mayor autonomía, ya sea en centralidad pura o plural, de manera que las personas pue dan tener más que ver con las orientaciones profundas que configuran sus vidas cotidianas.

\section{b) M odelo de centralidad en el trabajo reproductor}

Lo más importante en la vida cotidiana de estas personas es la actividad centrada en el cuidado de los demás, ya sea directo (hijos, otros familiares) ya indirecto (a través del cuidado de la casa). Trabajo productivo y tiempo libre desapa- 
recen 0 adquieren natural eza instrumental o subsidiaria. La simbología de esta centralidad no está hoy en la «perfecta ama de casa» - quizá lo fue así en el pasado- , sino en la importancia que para las personas tienen el hogar y la familia, lo cual, se supone, para funcionar bien tiene que tener una persona totalmente dedicada a ella. Es una centralidad que en un modelo puro la suponemos típicamente femenina.

Las transiciones en este modelo provienen fundamentalmente de una centralidad doble, productiva-reproductiva, que al ser asumida sólo por las mujeres se convierte fácilmente en doble jornada. 0 tro tipo de transición, por el contrario, puede ser la actividad en los dos ámbitos pero a tiempo parcial, lo que permite que hombres y mujeres busquen un protagonismo compartido en los dos ámbitos.

c) Modelo de centralidad en el tiempo libre

Siendo la nuestra una cultura eminentemente basada en el trabajo y la familia, el tiempo libre ha tendido a ser asumido bien como residual o bien como central para aquellas personas que todavía no tienen responsabilidades de adultos productivos (los jóvenes) o para quienes hayan salido del esquema de actividad, ya sea por la jubilación (en el caso de los hombres, puesto que a las mujeres les sigue quedando el trabajo reproductivo), ya sea por el simple tiempo de recuperación de la fatiga del trabajo. Por tanto, típicamente, el tiempo libre puede ser el centro de la vida cotidiana de adolescentes y jóvenes o de hombres viejos. Como quiera que la jubilación como derecho es un fenómeno reciente en nuestra vida cotidiana y en nuestro imaginario colectivo, de hecho la vida cotidiana centrada en el tiempo libre es vivida como algo que se ha perdido o que se puede perder, según la experiencia provenga de un adulto 0 de un joven.

Pero una de las novedades de la vida cotidiana en las últimas décadas es la entrada parcial del tiempo libre en la jornada diaria y, sobre todo, de fin de semana, de la gente. Ello ha podido acentuar los procesos de transición de centralidades puras en otros ámbitos a centralidades plurales, en las que un aspecto es el tiempo libre, valorado y querido en sí mismo y desarrollado autónomamente, al contrario del tiempo libre asumido meramente como recuperación o como ocio pasivo.

Por tanto, vamos a realizar a lo largo de estas páginas un triple análisis. En primer lugar, queremos estudiar la centralidad actual de la vida cotidiana de las personas, subrayando coherencias o incoherencias en la misma: es decir, analizando cómo se vive la articulación entre los ámbitos, tanto en términos materiales como de importancia relativa atribuida a uno u otro. En segundo lugar, queremos examinar las trayectorias, detectando lo que podríamos llamar «trayectorias típicas», con el fin de comprender las razones internas y contextuales que explican los modos de vida cotidiana. Por último, queremos analizar justamente las transiciones, intentando comprender por qué se desarrolla cada vez más la centralidad pluridimensional, lo que significa interrogarse sobre las nuevas circunstancias estructurales y los nuevos valores que 
puede haber en la base de los cambios; ello nos permitirá algún grado de previsión de lo que pueden ser formas de vivir que se podrían universalizar en el futuro, al menos que interviniesen nuevos e inesperados factores.

D ada la natural eza de estas estructuras de sentido, el método seguido de recogida de información ha sido el de las entrevistas semidirigidas y el de análisis temático cualitativo. Estos métodos y sus técnicas nos han parecido los más pertinentes al objeto de estudio, los más eficaces para obtener resultados y los más adaptados a un numeroso equipo de investigadores para un contenido como el de las articulaciones de ámbitos y de trayectorias de vida, biográfica y diaria, desde un nivel más informativo y objetual hasta el más simbólico, centrado en el descubrimiento interpretativo del sentido.

Esta parte constituye la tercera fase de la investigación, no sólo temporal sino también analíticamente, en el sentido de que es un nivel que se superpone a otro más objetivizado, el de las actividades o primer nivel, fase de análisis, y a otro, el segundo, más centrado en las representaciones y actitudes.

Las entrevistas no han sido totalmente libres, sino semidirigidas a partir de unas pautas muy generales dadas a cada uno de los entrevistadores que eran miembros del equipo. Estas orientaciones, en forma de preguntas abiertas, recorrían tanto la vida diaria como la trayectoria biográfica de las personas entrevistadas; la apertura de las preguntas permitía bifurcar la entrevista hacia aspectos que el entrevistador consideraba interesantes para nuestros objetivos.

Se han realizado veintiuna entrevistas, siguiendo los tipos o grupos de base descubiertos y utilizados precedentemente. Con todo, el número de tipos o grupos se ha reducido a cuatro, después de concentrar algunos de ellos. En el análisis de las entrevistas se resumen los contenidos básicos tomados en esta fase de la investigación, viéndose la identidad que guardan con los precedentes, salvo la asimilación de dos de ellos. Si bien se trata de entrevistas individualizadas, la elección no se hace al azar, ni se pretende tampoco un tipo de representación aleatoria: la elección parte del supuesto de que cada uno de los tipos de los que se extraen las entrevistas posee un elevado grado de homogeneidad, en cuanto a la distribución y articulación de actividades de los ámbitos productivo, reproductivo y de tiempo libre, de tal forma que se pueden inferir determinados supuestos con relación a las estructuras de sentido. Estas inferencias sobre la relación tipo o grupo y estructuras de sentido, no han de ser necesariamente de equivalencia total, por ejemplo, entre un tipo de centralidad objetiva en el trabajo productivo y centralidad en el mismo ámbito de sus construcciones simbólicas o de sentido. Precisamente, una de las cosas que más nos importaba es lo que más adelante denominamos «fenómenos de transición».

En cuanto al análisis, éste ha seguido en buena medida las pautas o componentes considerados en las estructuras de sentido, con un tipo de interpretación casi hermenéutica, a partir de una aceptación mínima de al menos determinados temas (ámbitos, articulación entre ellos, temporalidades y centralidad) como referentes de base. 


\section{La centralidad de la vida cotidiana: coherencias e incoherencias}

\subsection{Las modalidades (variedades) del tipo 1: ama de casa-madre de familia}

Primera variedad del tipo 1: el tipo 1 en «estado» puro

Se trata de mujeres que se dedican íntegramente al trabajo reproductivo, ocupando éste materialmente todo su tiempo de trabajo y valorativamente su universo de valores y relaciones, aunque contando con bastante tiempo libre y nada de trabajo productivo. El trabajo reproductivo puede tener una doble vertiente: el cuidado de la casa, que se mantiene con independencia de la edad de la protagonista - al menos mientras ésta sea físicamente capaz de realizarlo- y el cuidado del resto de la familia, mientras con esta persona vivan otros miembros de la familia, particularmente hijos y marido. N os encontramos, pues, ante la clásica vida cotidiana del ama de casa.

Pero dado que estas Ilamadas «cargas familiares» pueden variar ostensiblemente con la edad de las mujeres objeto de estudio, hemos contado con casos que cubran varias situaciones familiares.

Caso A) M ujer joven con hijos menores. D e clase media. $\mathrm{H}$ a dejado el mercado de trabajo, pero volvería - o volverá- si su puesto de trabajo fuese cualificado. Tiene poco tiempo libre a pesar de que salariza parte de las cargas domésticas. Por tanto, el trabajo reproductivo es central en su vida y de él dice encontrarse satisfecha. ¿Puede tratarse de que el trabajo productivo que puede prever le resulta poco atractivo? «C uando las niñas sean mayores, dice, volveré a la normalidad».

Caso B) M ujer de media edad con hijos ya mayores. Clase media baja. Total mente dedicada al trabajo reproductivo. Poco tiempo libre y éste se basa en las relaciones con amigas. El marido trabaja asal ariadamente. No tiene perspectivas de cambio, excepto poder pasear y viajar algo con el marido cuando éste se jubile. H abía dejado de trabajar al tener a los niños y nunca más volvió a hacerlo. D a mucha importancia a la familia y al trabajo doméstico.

Caso C) M ujer mayor que vive con el marido. Clase media alta. Trabajo sólo reproductivo, Ileva su casa y la de sus padres. N unca ha tenido trabajo productivo, pero ella cree que «es una jubilada que sigue trabajando». Tiempo libre muy variado y muy relacional, mujer culta y con medios. No vive su vida nada rutinariamente. Los cambios más importantes en su vida fueron de tener a no tener hijos y de tener criada a dejar de tenerla. Para el futuro teme que la lleven a una residencia.

Caso D ) Viuda mayor que vive sola. Fue trabajadora industrial hasta su jubilación. Lamenta no tener una familia a la que cuidar, pues su marido ha muerto y sus hijos viven autónomamente. No valora el trabajo reproductivo en sí mismo, sino como destinatario de la familia, mientras que sí valora en sí mismo el trabajo de la familia. Todo le lleva a proyectar su tiempo libre hacia el fin de semana, que puede pasarlo con sus hijos. 
Segunda variedad del tipo 1: un tipo no estrictamente puro

Este tipo posee algo de tipo 3, que consideraremos posteriormente; es decir, se trata de mujeres que siendo principalmente amas de casa tanto en dedicación como en concepción de su papel social, dedican sin embargo algún tiempo al trabajo productivo de manera informal, a veces en forma de tiempo libre a veces en forma de un trabajo asalariado, incluso sumergidamente. Esta dedicación productiva puede estar dictada por necesidades económicas, pero con frecuencia es también un engarce, actitudinal y relacional, con el mundo del trabajo que se tuvo en el pasado o que, quizá, se pretende volver a recuperar. Por ello su tiempo libre, al menos el que podríamos llamar «autónomo», queda reducido a la mínima expresión. H emos tenido en cuenta tres situaciones: que estas mujeres tengan hijos pequeños, que los hijos ya sean mayores o que no tengan hijos, dado que la vida cotidiana en un caso u otro puede ser radicalmente diferente, principalmente por el peso, en horas y en responsabilidad, que tendrán las tareas reproductivas.

La centralidad efectiva del ámbito reproductivo, la forma en la que dicha centralidad es asumida y el peso que tienen los otros dos ámbitos parece estar fuertemente condicionada, primordialmente por la existencia de hijos pequeños y secundariamente por otros factores como edad, nivel educativo y otros.

C aso A) Ama de casa de mediana edad, con hijos ya mayores. Se considera a disposición de la familia. Trabajó asalariadamente en su juventud, y después de criar a los hijos, en vez de volver a trabajar fuera, se dedica a ayudar al marido en la tienda de éste. Aunque parte de su tiempo libre sea trabajo reproductivo, se subordina al trabajo y a los objetivos del marido y de los hijos (cuida de los nietos), con renuncia a su propia autonomía del tiempo libre. Tiene la resignación como actitud vital primordial.

Caso B) M ujer de mediana edad, con hijos pequeños y nivel educativo alto. Tiene una profesión técnica a tiempo parcial, pero con dedicación plena a la familia, pues la profesión la realiza en casa. Su centralidad reproductiva, con todo, es flexible: tiene tiempo libre para ella y al gunas tareas están sal arizadas. Lo asume como un «ntercambio» informal con el marido.

C aso C) M ujer joven, sin hijos. Fue trabajadora industrial y ahora se dedica al trabajo reproductivo y muy parcialmente al trabajo productivo. Tiene tan asumida la importancia del trabajo reproductivo que lo glorifica y se considera un ama de casa perfecta y profesional. Asume la totalidad del trabajo reproductivo.

Sobre la coherencia de la centralidad en el tipo 1

¿H asta qué punto sólo el género o también la categoría socioeconómica son condiciones indispensables para la construcción de estas vidas cotidianas? Estas personas son mujeres casi siempre (en el caso de hombres que vivan solos lo que aparece es la doble centralidad), pero al mismo tiempo son sobre todo 
mujeres de categoría social baja y/o media. Las excepciones se dan cuando la situación de ama de casa se asume temporalmente, mientras que los niños son pequeños.

La centralidad reproductiva tiene principalmente dos modalidades: una como «centralidad instrumental»; otra como «centralidad simbólica». La primera acepta el modelo reproductivo como eje central de la propia vida pero en «aras de» la familia principalmente, o específicamente, del marido (y de su profesión): es la de la persona que vive «para otros». Por ello la calificamos de instrumental. La segunda asume las tareas reproductivas como el clímax de la propia existencia por obligación, porque debe ser así o porque es el papel que se ha decidido asumir. No siempre es fácil diferenciar ambas vertientes ni cada caso está nítidamente colocado en una de ellas. Pero ciertas líneas maestras pueden ser leídas desde esa perspectiva y la coherencia o incoherencia en la vivencia de la cotidianidad tiene bastante que ver con esto.

D edicarse a trabajar en el cuidado de la casa y de la propia familia, siendo ésta el objetivo último - por tanto centralidad instrumental- , puede dar una gran coherencia a la vida cotidiana de muchas mujeres que tienden a hacer girar en dicho entorno el resto de su vida. Justamente cuando la familia se deshace 0 se disgrega, pueden percibir en la insatisfacción que deja ese vacío la centralidad que para la propia vida tuvo la dedicación total a los suyos. Es una justificación de la forma de vida que podemos encontrar fácilmente en mujeres de categoría social baja, que sólo han trabajado asalariadamente en la juventud y luego se han retirado a sus casas, concentrándose sobre el círculo familiar hasta el extremo de hacer converger ahí no sólo el trabajo sino también el ocio. Con todo, para estas mujeres rige una doble centralidad: por un lado, la centralidad de la vida reproductiva que protagonizan, que casi siempre totalizan, y que es el eje de la propia vida y, por el otro, una centralidad de tipo productivo que en términos de socialización de la familia se asume como básica, pero que de hecho sólo se atribuye a la vida cotidiana del marido. En cierto modo, la familia como tal tiene una vida cotidiana y asume una doble centralidad complementaria dividida entre los dos principales miembros de la misma: la productiva por un lado y la reproductiva por otro. El tiempo de ocio y la importancia atribuida al mismo es secundario en estas vidas, en particular en la de la mujer. Como mucho, asume un papel «reparador» del trabajo productivo.

Pero hay una vertiente más «suave» de esta posición instrumental, bien dedicándose centralmente al trabajo reproductivo para la educación de los hijos mientras éstos son pequeños, o bien dedicándose al marido para su consolidación profesional y, por tanto, durante un período de tiempo limitado. Justamente lo que diferencia esta vertiente de la centralidad reproductiva respecto de la anterior es que las mujeres - puesto que son casi siempre mujeres las que se encuentran en tal situación- asumen esta centralidad temporalmente, manifestando así que no se trata del único punto de referencia de sus vidas cotidianas, sino que la suya es una central idad doble porque dan mucha importancia al trabajo productivo. La indicación de esto la tenemos en la forma en que describen el trabajo de las otras mujeres, en que hablan del que tuvie 
ron o en la voluntad de volver cuando pase el período de excepcionalidad. Es muy posible que no vuelvan, quizá porque el trabajo que tuvieron y el que pueden esperar después del período de interrupción, es muy descualificado y poco satisfactorio. Pero una cosa es la satisfacción o insatisfacción con el propio trabajo productivo y otra el tono que a la propia vida da el ocuparse en un trabajo productivo, principalmente a tiempo pleno y reconocidamente, o no hacerlo.

Aún hay otra versión de esta centralidad reproductiva instrumental, en este caso no en aras de la familia, de los hijos o del marido, sino de sí misma: la mujer que acepta la división «tradicional» del trabajo que le atribuyen las tareas reproductivas a cambio de más libertad para sí misma, sea ésta para realizar un trabajo productivo flexible y adaptable a cambios - el trabajo a domicilio de nivel profesional alto, algún tipo de trabajo esporádico fuera de casa, etc.- , sea para gozar de más tiempo libre. Respecto a estas personas, cabe decir que tampoco su centralidad es reproductiva en términos de valores, sino que normalmente manifiestan una centralidad pluridimensional a través de la cual buscan una vida cotidiana rica y equilibrada. Es decir, pueden dedicar muchas horas al trabajo reproductivo, pero ponen el acento sobre sus ratos de trabajo profesional o de ocio.

La vertiente que hemos llamado «suave» de la centralidad reproductiva instrumental suele estar protagonizada por mujeres de categoría social media, con un cierto nivel de estudios y que, con frecuencia, tienen recursos económicos como para salarizar las tareas domésticas más duras. Estas mujeres, pues, buscan una coherencia nueva en sus vidas cotidianas. Asumen el trabajo reproductivo, pero sólo en parte, lo protagonizan y demuestran en una palabra que sus vidas cotidianas giran no sólo en torno a aquello a lo que más horas dedican, sino también a otros aspectos que, menores en cantidad, son apreciados por la calidad de vida que ofrecen.

Por el contrario, la centralidad simbólica del trabajo reproductivo hace a éste importante por sí mismo. También en esta modalidad hemos encontrado dos versiones que difieren en cuanto a la valoración del trabajo reproductivo. La más común es aquélla que vincula la dedicación de la mujer primordialmente al rol reproductivo «porque así debe ser», «porque es su obligación». Con frecuencia estas mujeres han trabajado fuera de casa hasta que se han casado y luego han asumido la nueva vida como una imposición externa que a veces se ha canalizado hacia el servicio a la familia y a veces se ha vivido con insatisfacción 0 , cuando menos, con resignación. La centralidad total de la reproducción en la vida cotidiana que se da en esta modalidad no supone satisfacción necesariamente, pues suel e limitar otras expectativas vitales. También en este caso suele tratarse de mujeres de categoría socioeconómica baja, sin estudios, de edad media 0 avanzada.

La versión más laica la vemos protagonizada más bien por mujeres de categoría media o de origen bajo con movilidad ascendente, en general jóvenes. Estas mujeres asumen una división sexual estricta del trabajo: el marido tra baja fuera y ellas dentro de casa, asumiendo todo el trabajo con un talante casi 
profesional: ser buena cocinera, ser ahorradora, saber llevar la casa. D esde un cierto punto de vista responden fielmente a la socialización recibida: la mujer ha de ser principalmente madre y ama de casa. Su vida cotidiana responde con gran coherencia a esta pauta hasta el punto que casi toda su actividad es reproductiva. En el tiempo libre se busca una cierta compensación, aunque no de manera autónoma: salir con el marido a pasear, o de fin de semana o hacer viajes, en función del nivel social y de ingresos al que nos estemos refiriendo.

En resumen, podemos decir que la consistencia de la centralidad reproductiva de la vida cotidiana depende más de factores sociales que de factores personales. Es decir, está más ligada a formas de división sexual del trabajo, a formas de socialización, a categoría social, a nivel de ingresos, etc., que a deseos y aspiraciones personales.

\subsection{Las modalidades (variedades) del tipo 2: el hombre ocupado en el trabajo productivo de manera absorbente}

Este tipo está compuesto mayoritariamente de hombres - puede haber también mujeres- centrados en el trabajo productivo, con nula o escasa dedicación al trabajo reproductivo - que realiza para ellos una mujer de la familia- , y con poco tiempo libre. Su vida cotidiana (grado de dedicación a los tres ámbitos, prioridades de uno u otro, actitudes, etc.) puede estar marcada también por la edad, la educación, los hijos y la edad de los mismos, pero sobre todo está condicionada por su trabajo profesión. Los casos escogidos pretenden cubrir estos factores que diversifican la común dedicación al trabajo productivo.

Caso A) El primero es el caso de un hombre joven, recientemente casado e independizado, sin hijos, totalmente centrado en su trabajo durante la semana y en el tiempo libre el fin de semana; un tiempo libre rico, variado y relacional. Sus problemas reproductivos los resuleve en parte su mujer - que también trabaja asalariadamente- y en parte su madre, en casa de la cual come cada día.

Caso B) El nivel de estudios y la categoría social superiores son la principal diferencia entre este caso y el anterior. Percibe el trabajo reproductivo de manera negativa - «contribuye en lo que toca»- y defiende su tiempo libre como el espacio de intimidad. Al ser joven, la importancia que da a su profesión es algo que más bien se proyecta hacia el futuro, sin pensar tanto en el presente.

Caso C) H ombre de mediana edad, con hijos mayores y mujer que desempeña el típico papel de ama de casa. Aunque el trabajo/profesión es el centro de su vida, el tiempo de ocio, con dedicación a sí mismo y a la familia, ha ido ganando espacio. Con otras palabras, se muestra satisfecho y embebido por el trabajo profesional, pero defiende un espacio y un tiempo para el ocio que, en general, queda circunscrito al fin de semana. Pero también es en el tiempo libre donde sueña, en un futuro, rehacerse de al gunas frustraciones. Tal bicen- 
tralidad, con todo, se sustenta claramente en el hecho de que el ámbito reproductivo lo tiene totalmente resuelto.

Caso D) Éste es el caso de un hombre, de clase media baja. En su hogar, el trabajo reproductivo tiene la «carga» suplementaria de hijos menores y la mujer también trabaja en el mercado. El trabajo productivo es el dominador común de la vida cotidiana de esta persona, hasta el punto que, si es necesario, alarga su jornada lo que sea necesario. Con todo, lo vive muy instrumentalmente ( $« \mathrm{si}$ no trabajo no vivo»). D efiende el espacio y tiempo de no trabajo, pero mientras que en el ocio él quiere ser el rey - hacia éste deriva la satisfacción que no parece encontrar en el trabajo- , en las tareas domésticas la reina y ministra plenipotenciaria - porque lo hace todo- es su mujer.

Caso E) Es el caso de un hombre de mediana edad, con estudios superiores, de categoría media e ingresos altos. T iene hijos pequeños y les dedica bastante tiempo. M aterialmente, su vida cotidiana está dividida entre trabajo productivo, trabajo reproductivo y tiempo libre. Pero su corazón está con el prime ro, salarizaría el segundo totalmente si pudiera, mientras que el tercero lo concibe en términos muy productivistas (no sabe «perder» el tiempo). Podríamos hablar de centralidad en transición, si nos atuviéramos a las horas del día que dedica a cada cosa, pero la mentalidad del entrevistado es productivista.

Caso F) Se trata de una mujer joven, recién licenciada, que dedica todo su tiempo a estudiar para preparar oposiciones. $\mathrm{H}$ a prescindido - aunque sea temporalmente, pero durante un largo período- totalmente del tiempo libre. El trabajo reproductivo está resuelto completamente por su madre.

La centralidad de la vida cotidiana en el tipo 2

El modelo tradicional centra la vida cotidiana en el trabajo productivo; no sólo en términos materiales, sino también, y sobre todo, en términos de valores y símbolos. L os otros ámbitos quedan reducidos, ignorados o vividos a través de su traducción a lo productivo. Cuando se trata de personas que viven en familia, esa centralidad de la propia vida cotidiana se apoya en otras personas que solucionan las tareas de reproducción; es, por tanto, una centralidad apoyada. Con todo, este último aspecto, es decir, si se dedica un tiempo consistente o no al trabajo reproductivo, puede señalar variantes al modelo; también ocurre en función de si la persona con la que se vive está o no ocupada en el ámbito del trabajo productivo, lo que comportaría una presión sobre dicha centralidad productiva.

Entre quienes materialmente se centran en el trabajo productivo, podemos diferenciar dos vertientes, tal como ya veíamos en el tipo uno: la de «centralidad productiva instrumental» y la de «centralidad productiva simbólica». En la primera, el trabajo absorbe materialmente la mayor parte del tiempo y de los esfuerzos de la vida cotidiana, pero es asumido simplemente como un instrumento para ganarse la vida, para mantener la propia familia, sin ser altamente valorado en sí mismo; más aún, viviéndolo con frecuencia como 
insatisfactorio y rutinario. La otra vertiente es la de un trabajo altamente valorado, que es el centro del discurso, que no sólo ocupa materialmente el tiempo sino que constituye una base importante de los valores de la persona. Edad, nivel de estudios y cualificación del trabajo son seguramente las variables que más inciden en que la centralidad de la vida cotidiana se decante hacia una o hacia otra vertiente. La segunda interpretación del trabajo productivo es vivida mucho más coherentemente que la primera, porque los val ores que pueden ser el soporte de ésta quizá están fuera del ámbito productivo: son la familia o la solidaridad o la supervivencia.

Con todo, éstas son las vertientes que podríamos llamar «tradicionales» de la centralidad productiva, básicamente vivida dentro del género masculino. D os grandes cambios se dibujan en los últimos años, de acuerdo a lo que pode mos captar en el conjunto de la investigación: el proveniente del ámbito del trabajo reproductivo y el que se refiere al ámbito de lo personal y/o del tiempo libre. En el primero encontramos casos de hombres que asumen una parte notable del trabajo reproductivo y del cuidado de los hijos juntamente con su ocupación productiva. Suelen tener estudios medios o superiores y ubicarse en profesiones referentes a capas medias. Con todo, siguen manifestando una vivencia cotidiana diferente entre uno y otro tipo de trabajo: el productivo suele ser altamente valorado e informa el resto de la vida con categorías eficientistas o productivistas; el reproductivo es asumido, efectivamente, pero como al go rutinario y poco satisfactorio, o como una carga que se salarizaría si fuera posible. Es decir, se trata de una centralidad bipolar materialmente hablando, pero unidimensional aún en términos más profundos. Con todo, se apuntan aquí fuertes tendencias que pueden conducir a cambios notables, lo que se da - sobre todo - cuando las personas que habitual mente habrían sido el apoyo reproductivo, las mujeres, también tienen una ocupación productiva. Se trata de una centralidad productiva con contradicciones e incoherencias provenientes de las exigencias de la vida doméstica y familiar, independientemente de la importancia simbólica que siga teniendo.

Esta tendencia de cambio es culturalmente la más relevante, la que más incidencia cualitativa parece tener, pero por eso mismo puede que avance con lentitud. $\mathrm{H}$ ay otra mucho más extendida que refleja la importancia que en la vida cotidiana tiene el tiempo libre o la dedicación a actividades o intereses estrictamente personales. Consiste en centrar la propia vida cotidiana en parte sobre el trabajo productivo, pero reservando sistemáticamente una parte del día, o el fin de semana, para actividades que no son meramente de recuperación, sino de desarrollo de ciertas cualidades o deseos. Estamos ante una centralidad bipolar donde el peso del tiempo libre en términos de valores y símbolos puede ser muy fuerte. Es una centralidad productiva incoherente por la presencia de la otra.

\subsection{Las modalidades del tipo 3: mujeres, fundamentalmente con doble jornada}

El tipo 3 capta la situación de las mujeres - y raramente de algunos hombres- con doble presencia y doble jornada. Es decir, aquellas mujeres que tie- 
nen trabajo productivo, con bastantes horas ocupadas en el trabajo reproductivo y con poco tiempo libre. Suelen ser de categoría social media-alta, de mediana edad, muchas de ellas con estudios. Las situaciones típicas varían fundamentalmente en relación con dos factores: si tienen o no hijos, principalmente en edad que requiera una alta dedicación; si tienen o no marido o compañero, lo que podría suponer la posibilidad de distribuir el trabajo reproductivo.

Con todo, el eje que estructura valores y comportamientos en su vida cotidiana es la importancia que se atribuye bien al trabajo productivo o bien al reproductivo. Las formas condicionadas que aparecen son las siguientes:

- El trabajo reproductivo es repartido entre la pareja, en general con algún grado de externalización (pagando una parte a otra persona).

- El trabajo reproductivo está poco repartido y casi totalmente salarizado en una persona externa que se ocupa muchas horas del mismo.

- Lo hace sólo la mujer en doble jornada (no parece darse el caso contrario).

- Lo hace una sola persona (hombre o mujer) porque vive sola.

Caso A) Es una mujer viuda con hijos mayores, de clase trabajadora. Realiza una doble jornada y mantiene doble presencia - en el ámbito productivo y en el reproductivo- después de un intervalo de diez años para criar a los hijos. Trabajó asalariadamente desde los dieciséis años, y cuando estaba casada no tenía tiempo para nada; dice que era un infierno. Sus vivencias se centran en el trabajo productivo y en el tiempo libre, aunque por razones muy diferentes. En efecto, el primero no acaba de gustarle - «no se realiza», señala— , al tiempo que añora disponer de más tiempo para el segundo.

C aso B) Se trata de una mujer que trabaja a jornada completa, separada, con un hijo y con posición social media. D edica poco tiempo a la casa, el resto del trabajo doméstico lo paga. El tiempo libre está concentrado al final de la jornada y en los fines de semana; consiste sólo en leer y en estar con su hijo. Q uiere promocionar en el trabajo, aunque debería reciclarse; para ello necesita las tardes. Pero esto choca con el tiempo dedicado al hijo, que para ella es lo más importante desde la separación.

C aso C) M ujer soltera, de mediana edad. Trabaja y se ocupa de la casa y de su madre inválida, aunque tiene una chica que le ayuda a horas. Le gusta su trabajo y tiene las tardes libres, que pasa en casa, aunque recibe visitas de amigas. Le gus tarían algunos cambios en el futuro, pero lo ve condicionado por la invalidez de la madre. Como tiene poco tiempo libre, lo proyecta en el fin de semana, aunque desearía aumentar su tiempo de ocio. Si pudiera volver a empezar estudiaría una carrera. Su centralidad material es la productiva, pero su centralidad simbólica es el tiempo libre. $M$ aterialmente, hay un equilibrio entre los tres ámbitos. Las rupturas principales en su vida han sido la enfermedad de su madre, porque ello le hizo cambiar la manera de vivir, dado que vivía sola, y cambiar hacia un trabajo mucho más satisfactorio que el que tenía. 
Caso D) M ujer casada, con trabajo productivo y reproductivo (para el que tiene al guna ayuda externa) y sin nada de tiempo libre, excepto por las noches. Al trabajo productivo dedica el máximo tiempo, al reproductivo, un tiempo limitado y organizado, y el tiempo de ocio - el de ella y el de la familia- lo preserva como un bien preciado. El marido aparece como mero acompañante, nunca sale en primer plano. Identifica la ruptura en su vida cotidiana con el nacimiento y la crianza de sus hijos, vinculándolos a la disponibilidad de tiempo. Piensa en un futuro en el que todo seguirá igual (no tiene proyectos), por más que el trabajo doméstico no le gusta. D efine su vida por la estabilidad, que más bien se podría interpretar como aburrimiento.

Caso E) Es un hombre casado, de mediana edad, con dos hijos pequeños y buena posición laboral y económica. Su mujer es empresaria. Se dedica intensamente a su trabajo, aunque con un horario estricto. Señala que «o doméstico» está repartido - en el fondo, se trata de que deciden democráticamente cómo gastan el dinero- entre él y su mujer, aunque su papel parece más bien instrumental; mejor dicho, ni él ni su mujer le dedican mucho tiempo, porque tienen una persona pagada durante muchas horas. D a mucha importancia al tiempo libre, pero lo describe no en términos familiares, sino en círculo de amigos. Sus rupturas son el nacimiento de los hijos y el hecho de que su mujer se haya puesto a trabajar. Para el futuro sueña con más viajes y más vacaciones.

Caso F) Es un hombre joven, de clase media, buena posición económica y trabajo interesante. Vive solo desde hace tres años. Realiza todo su trabajo reproductivo, aunque lo reduce al mínimo. También le gustaría reducir el tiempo de trabajo productivo, aunque le gusta, puesto que lo que quiere es aumentar el tiempo de ocio. Q uiere tiempo para él y disfruta el fin de semana, el cual pasa, con frecuencia, solo. Lo que de verdad le interesa es poder ser dueño absoluto de su tiempo.

Caso G) Se trata de una mujer joven con hijos pequeños, ingresos bajos y mentalidad de clase media. Su vida cotidiana aparece articulada en torno a dos temas centrales: la casa y la familia y su trabajo. El tiempo libre desaparece del horizonte y, en cierto modo, se mezcla con al reproductivo (jugar con los hijos). D e todos modos, el hilo conductor de ambos ámbitos parece ser más la importancia de la familia que la del trabajo. El hombre con el que vive pasa como una sombra - «no tiene tiempo ni está preparado para el trabajo doméstico»- y en el fondo de una vida materialmente distribuida entre el trabajo fuera de casa y dentro de casa aparecen unas estructuras de sentido que se definen por el convencimiento de que «es normal que la mujer trabaje fuera de casa, pero sin olvidar lo doméstico, puesto que está especialmente preparada para eso». Con otras palabras, la centralidad productiva está soportada, en el caso de la mujer, por la centralidad reproductiva.

Caso H ) Es una mujer cercana a la jubilación, aunque de baja por larga enfermedad. Pero aunque sigue ocupándose de su familia y de las cuestiones domésticas, excepto en los aspectos que la enfermedad le imposibilita, el trabajo 
productivo no ha desaparecido de su universo de valores y representaciones. Con todo, a pesar de haber trabajado durante treinta años, ese trabajo no ha desplazado la centralidad de lo doméstico. D el trabajo doméstico habla como de lo más natural del mundo, mientras que el productivo no ha generado en ella ni amigos ni relaciones y es descrito como al go duro. Como tiempo dedicado a sí misma hay que destacar lo que se deriva de sus profundas convicciones religiosas que, probablemente, procuran una cierta conformidad con la vida, tal como le ha venido. Se observa en ella una doble centralidad, la productiva, aunque animada por la reproductiva, en una vida profundamente resignada y aceptada como viene, sin que uno pueda hacer mucho para modificarla.

Caso I) Se trata de una mujer de mediana edad, con nivel al to de estudios, con hijos de corta edad y con un empleo satisfactorio. El empleo es lo que más le interesa, lo cual la lleva a salarizar todo lo que puede el doméstico, excepto el cuidado de los hijos. Su tiempo libre, aunque escaso, es celosamente guardado y en gran parte disfrutado no en términos familiares - aunque eso no se excluye- , sino en relación con sus amigos de trabajo. El trabajo profesional es básico para ella. Puede distribuir el doméstico, pero cree que su marido no lo asume con su mismo grado de responsabilidad, lo que le hace pensar que durante un tiempo - mientras los niños sean pequeños- estará disminuida - por ejemplo, en términos de promoción o de puesta al díaen su trabajo profesional. Eso le lleva a mirar el trabajo doméstico negativamente. Es una centralidad bipolar, donde, asumiendo la importancia del trabajo profesional, no desea que el doméstico sea razón de minorización de aquél.

C aso J) M ujer joven, casada, con hijos pequeños, con dedicación al trabajo productivo y al doméstico - en este terreno el papel del marido es instrumental, aunque dedica muchas horas - y bastante tiempo libre. El trabajo productivo lo ha entendido siempre como una reafirmación de sí misma; el reproductivo como una obligación ineludible, y el tiempo libre como una dedicación a la sociedad. Es un caso de triple centralidad basada en la reafirmación de la propia personalidad. Pero esta triple centralidad en términos de valores se ve condicionada por la centralidad material que, al menos por ahora, impone el trabajo reproductivo, particularmente el cuidado de los hijos.

Sobre la coherencia en el tipo 3

$\mathrm{H}$ emos considerado y analizado muchos casos, puesto que consideramos que aquí se está dando una importante transición en la vida cotidiana que conviene estudiar en detalle. D icha transición es conceptuable como bicentralidad - vida cotidiana basada en el trabajo productivo y el reproductivo- que afecta sobre todo a las mujeres, pero también a algunos hombres. Se trata de personas que balancean su vida cotidiana entre el trabajo productivo que realizan fuera de casa y el reproductivo que llevan a cabo en el hogar y la familia. Encontramos varias modalidades. 
En una primera modalidad son personas que basan la coherencia de su vida cotidiana en la actividad reproductiva. Consideran que ésta es « o natural o lo que se debe hacer», o lo que uno no tiene más remedio que hacer para poder dedicarse a lo otro, que es la profesión, siendo el objetivo en general el bien de la familia y lo asumen con este sentido del deber o de la evidencia - a veces, de la fatalidad y de la resignación-, reduciendo el trabajo productivo a al go complementario. Por ello, la valoración del trabajo productivo en la vida cotidiana aparece como en sordina, a pesar de que lo llevan a cabo. Asimismo, en las relaciones sociales y el tiempo libre apenas se nota alguna repercusión del ámbito del empleo, sino que se basan precisamente en las tareas reproductivas. Por tanto, la suya es una bicentralidad incoherente, puesto que la fuente de la coherencia está en la función reproductiva.

Una variante de dicha modalidad la tenemos en basar la coherencia de la vida cotidiana en la dedicación a la profesión, asumiendo que lo reproductivo tiene que hacerse porque no hay más remedio, 0 al menos durante un cierto período. Por eso se reparte, con fortunas desiguales, se salariza en parte 0 , si no, se soporta (más la mujer que el hombre cuando viven en pareja). También aquí podemos hablar de bicentralidad incoherente, puesto que la fuente de la coherencia sería un trabajo profesional que no se puede desarrollar todo lo que se desearía.

La segunda modalidad es, precisamente, la de coherencia en la bicentralidad. Se produce cuando se da igual importancia a una y otra actividad; a la una por desarrollo propio y a la otra por solidaridad con el grupo familiar. La forma que entonces adquiere la vida cotidiana está en estrecha relación con las posibilidades de distribuir el trabajo reproductivo, puesto que mientras que una parte de éste es suficiente para demostrar esa solidaridad, se requiere todo el trabajo productivo a tiempo pleno para reafirmar el propio desarrollo y autonomía. Es poco frecuente el caso de mujeres que puedan contar con un reparto equilibrado del trabajo reproductivo, lo que las lleva a una percepción negativa del mismo - porque les impide su desarrollo pleno- o a acentuar la importancia del trabajo productivo.

U na tercera modalidad de coherencia es la de tricentralidad: trabajo productivo, trabajo reproductivo y tiempo libre. Q ue la consigan las mujeres más fácilmente que los hombres se explica porque ellas han tenido que luchar por salir del espacio que socialmente se les había asignado y entonces han querido hacerlo buscando una vida cotidiana lo más plena posible. Pero en general, en estos casos las mujeres pueden tener que pagar, y el pago es cargar casi totalmente con el trabajo reproductivo, sacando tiempos de la salarización de una parte del mismo, cuando los ingresos les permiten hacerlo.

Como observación general podríamos señalar que la mayoría de los casos se sienten fuertemente atraídos por la llamada de atención y reclamación de más tiempo de libre disposición, o tiempo de ocio, que hace pensar que tanto las vidas centradas en el trabajo productivo como aquéllas centradas en el trabajo reproductivo, o sobre ambos al mismo tiempo, aparecen para mucha gente 
como vidas descentradas si no dedican a la persona en su totalidad el tiempo suficiente para desarrollar sus aspiraciones más íntimas.

\subsection{Las modalidades del tipo 4: las personas jubiladas}

Las personas cuya vida se centra principalmente en el tiempo libre pertenecen a dos colectivos: personas de edad y jóvenes de ambos sexos. Los primeros, jubilados, no tienen actividad productiva, pueden o no tenerla reproductiva y gozan de mucho tiempo libre. Lo diferencial de los segundos suele consistir en que están estudiando o bien no han logrado entrar aún en el mercado de trabajo como ocupados. D ado que el grupo de los jóvenes refleja una etapa transitoria de la vida, nuestra atención se va a centrar aquí sobre los primeros. Las variantes a contemplar son que, además de convivir con una persona que asuma las tareas reproductivas, tengan al gún tipo de responsabilidad directa, 0 no, sobre familiares a su cargo, lo que se reduce, en realidad, a variantes de género.

Caso A) Se trata de un hombre de más de sesenta y cinco años, jubilado, aunque esporádicamente realiza trabajos, con un nivel de estudios altos, técnico alto en su día, con ingresos medios. Sigue tan centrado sobre el empleo que, aunque sea en términos de afición, aquél sigue captando todo su tiempo libre. La razón se debe a que se trata de una actividad tan creativa que llena totalmente su vida, borrando las fronteras entre trabajo y tiempo libre. Pero puede ser así, en buena parte, porque su trabajo reproductivo está solucionado por otras personas (su mujer). D e manera que esa nueva centralidad, mezcla de trabajo y ocio, se da porque hay un soporte que realizan otras personas. La novedad es que esta persona tiene un total control de su tiempo, que no sería posible si tuviera que trabajar obligatoriamente. Eso es lo que nos permite decir que su centralidad es el tiempo libre.

Caso B) H ombre, recién jubilado, con hijos que viven aún en casa. Sigue con algún tipo de actividad, puesto que era autónomo. Contrariamente al caso anterior, éste sigue trabajando porque la pensión de jubilación le resultaría insuficiente para vivir. Pero el trabajo profesional está tan metido en su vida que ni se plantea el trabajo reproductivo; ve normal que lo realice su mujer como antes su madre. Sí piensa en el tiempo libre, al que da una fuerte simbología liberadora: piensa en futuros viajes, sale cuanto puede los fines de semana, etc. Es como una necesidad de recuperar lo que no ha hecho hasta ahora, lo que permite sospechar que el trabajo en sí mismo no le ha satisfecho tanto como decía. Esa insatisfacción de un trabajo que no pudo escoger es lo que le lleva a desear que los hijos puedan estudiar para que puedan escoger.

Caso C) Es una mujer de edad avanzada y difícil movilidad, jubilada de un trabajo de baja cualificación (vendedora) y con ingresos bajos. Vive con una hija, lo que explica que apenas tenga cargas reproductivas. Sus recuerdos están 
Ilenos de su empleo pasado. En el momento presente, su vida está centrada en el tiempo libre: leer, no hacer nada, recibir visitas, hablar del pasado, un pasado lleno de la actividad productiva y de amistades y relaciones tejidas en torno a la misma.

Caso D) Es una mujer de edad avanzada, soltera, jubilada, con bajos ingresos y que vive sola. En el presente, su vida cotidiana está dominada por un trabajo reproductivo reducido al mínimo y por el tiempo libre, en el que el cuidado de sí misma - arreglarse, pasear, leer - y las amistades tienen un papel central. A pesar de ello, su vida cotidiana está profundamente marcada por la soledad y por los recuerdos. Su vida es muy rutinaria, no hay diferencias entre la semana y el fin de semana, no hay vacaciones ni acontecimientos extraordinarios.

\section{La coherencia en el tipo 4}

Podríamos pensar que la coherencia de la vida cotidiana en este tipo se debería basar en una dedicación bastante plena al tiempo libre, en una alta valoración del mismo y en un fuerte aprecio a las cosas que en él se hacen y a las relaciones que gracias a él se pueden desarrollar. Pero en la realidad podemos encontrarnos, al menos, con cuatro tipos de situaciones o modalidades que contribuyen a matizar esta perspectiva.

La primera y más frecuente es una situación de incoherencia vital, a pesar de que una gran parte - la mayor parte- del tiempo diario de estas personas debería ser tiempo libre. Es una incoherencia de orden material: aunque de hecho habían entrado en la edad de jubilación, las personas siguen teniendo que dedicarse en gran parte al trabajo productivo 0 al reproductivo. Pero también es una incoherencia de orden simbólico, dada la importancia que en todo orden de cosas se sigue atribuyendo tanto a lo productivo como a lo reproductivo. D e hecho, podemos decir que una de las otras central idades del pasado sigue superponiéndose a la que materialmente ocupa el presente. La centralidad productiva se superpone por necesidad o por convicción, igual que por necesidad o por obligación se superpone la centralidad reproductiva. Pero en realidad son la cultura laboral o la familiar tradicionales las que están detrás; lo están con tanta fuerza que la gente no es capaz de desprenderse del rol que en dicho marco cultural ha jugado toda la vida.

La segunda situación es aquélla en que aún con plena dedicación al tiempo libre, gran parte de los valores, de las referencias - a veces vividos en primera persona a veces como proyección sobre los hijos- están referidos al trabajo reproductivo 0 al productivo. El tiempo libre no acaba de tener su propia autonomía y no domina coherente y totalmente el espacio vital más allá de la materialidad. 0 bien tiene una centralidad mezclada con uno de los ámbitos anteriores. No hay casos de ruptura.

Luego tenemos la vida de aquellos que, cogidos por las necesidades que se derivan de lo productivo o de lo reproductivo, a pesar de lo avanzado de su edad, viven el ocio de una manera muy simbólica. D esearían hacer viajes, sue- 
ñan con haber tenido oportunidades que no han tenido. La falta de tiempo 0 la falta de medios les dificultan el disfrute del tiempo libre que desearían.

Por último, tenemos la situación de ancianos, por encima de los setenta y cinco o de los ochenta años, cuya vida cotidiana, sin nada que hacer en los ámbitos productivo y reproductivo, está sin embargo marcada por la enfermedad - que, por ejemplo, les impide moverse y relacionarse - o por la soledad - derivada de la pérdida de amigos y parientes- , lo que dificulta la vivencia de una cotidianidad autónoma.

Por tanto, lo característico de esta tipología es la falta de vivencia con plena autonomía de su vida cotidiana de tiempo libre. Tal falta de autonomía puede estar impuesta por la necesidad, pero con más frecuencia lo está por la fuerza que tienen pautas culturales que han tendido a considerar el tiempo libre en términos exclusivamente subordinados: reponer fuerzas, por ejemplo. No hay una socialización fuerte como para asumir la nueva etapa en toda su ple nitud.

Con todo, en algunos casos se comienza a abrir paso tímidamente lo que puede ser una nueva perspectiva de vida cotidiana, la de dedicarse plenamente al goce del tiempo libre después de la jubilación. Se percibe en la fuerza que adquieren en el imaginario de las personas, por ejemplo, los viajes que se pueden hacer, la dedicación a cosas para las que no se había tenido tiempo en eta pas anteriores, la posibilidad de dedicarse a actividades en que no se percibe la frontera entre el trabajo y el tiempo libre porque ambas se real izan con gran satisfacción. El punto de ruptura hacia un nuevo modelo cultural puede estar apareciendo aquí. Un modelo en el que la autonomía de la persona sea lo más apreciado, por encima de la actividad material que realiza.

\section{Las trayectorias biográficas como corriente de fondo de la vida cotidiana}

La trayectoria de la vida cotidiana de las personas desde su juventud podría ser entendida como la sucesión y posible cambio de centralidades, en el supuesto de que tanto factores internos - deseos, objetivos, intereses- como factores externos - los procesos de socialización y las coyunturas sociales en las que a uno le toca vivir- pueden condicionar tal cambio.

El análisis sobre trayectorias de la vida cotidiana tiene el objetivo de contemplar cómo formas de vida cotidiana que aparecen social y culturalmente muy estandarizadas sufren diversos y sucesivos cambios. Los posibles cambios contemplados en la globalidad de la vida de las personas son lo que desde la perspectiva de la sociología puede tener más interés, puesto que son ellos los que explican la complejidad de dicha vida cotidiana. En este apartado vamos a describir, pues, algunas «trayectorias estándar», mientras que en el siguiente, el apartado 4, intentaremos una aproximación más estricta al cambio 0 a las transiciones que se producen en la actualidad.

Aunque tal análisis tiene en cuenta los cuatro «tipos» a los que, con frecuencia, nos hemos referido en esta investigación, el eje fundamental del reco- 
rrido será el género, dada la substancial diferencia de centralidades entre hombres y mujeres, casi constituida como constante histórica.

Por último, cabe decir que en el análisis conviene diferenciar dos niveles: el objetivo, que tiene en cuenta los hechos más importantes de la vida de las personas - que en nuestro estudio son hechos exclusivamente referidos a uno u otro de los ámbitos estudiados- y el subjetivo, que es la forma en la que la gente percibe el transcurrir de su vida, que no es otra cosa que la comparación de la propia vida con una «trayectoria estándar» que es la dominante.

\subsection{Trayectorias de mujeres}

D esde el punto de vista de las vivencias subjetivas, lo que probablemente adquiere mayor relevancia es que las mujeres se ven envueltas - por diversos motivos- en una división sexual del trabajo que les atribuye todas o las principales responsabilidades del trabajo reproductivo. Lo asumen para toda la vida, aunque las razones sean diversas y el grado también. Lo asumen con frecuencia desde una posición débil, es decir, creen que tienen pocas posibilidades de que sea de otra manera.

La mejor forma de analizar las trayectorias de la vida cotidiana de las personas en esta situación es aplicar un corte por edad: diferenciar entre mujeres jóvenes, mujeres de mediana edad y mujeres de edad avanzada. La razón es que la amplitud de la trayectoria es clave. Además de esto, otros factores que veremos pueden ser relevantes.

\section{Lasjóvenes}

Las mujeres jóvenes que en este momento son amas de casa, han pasado en general por uno, dos o tres estadios anteriores, en los que su vida cotidiana giraba sobre otras bases. Prácticamente ya no existe de forma exclusiva la trayectoria tradicional que de una juventud dedicada a una misma (tipo 4), llevaba a las mujeres a convertirse en amas de casa (tipo 1) sin más y para toda la vida. Se dan otras dos trayectorias: la de quienes primero se han dedicado al trabajo productivo y luego, al casarse o al tener hijos, han asumido en su totalidad el trabajo reproductivo del nuevo grupo, renunciando a su trabajo productivo; y la de quienes han mantenido este trabajo productivo durante el primer tiempo, compartiéndolo unos años con el otro a base de doble jornada y doble presencia y luego se han dedicado al papel de madres cuando han tenido los hijos.

En la definición de estas dos trayectorias un fenómeno adquiere gran importancia: el trabajo productivo. Por comparación con la trayectoria de otras mujeres y por la comparación que ellas mismas hacen con otras, podemos percibir que la mujer moderna en nuestra sociedad mantiene con mucha frecuencia el doble trabajo después de casarse, pero lo mantiene al tener hijos sólo si es un trabajo profesionalmente satiffactorio o que abra el campo a la propia autonomía o fortal ecimiento de la individual idad o a relaciones sociales muy satisfactorias; cuando no es así, vuelve a prevalecer la pauta tradicional de la rígida división. La excepción es la necesidad acuciante de ingresos, que obliga a man- 
tener dicho trabajo productivo, aunque instrumentalmente; o bien la comodidad de ingresos que permiten salarizar parte de las tareas domésticas.

Esto nos dice algo de la importancia que tiene el trabajo productivo en la configuración de la vida cotidiana en nuestra sociedad. Cierto que la mujer suele necesitar para ello el recurso a la doble jornada, a veces corregida con la salarización parcial del trabajo reproductivo. En cierto modo, podríamos resaltar dos cambios relevantes en la vida cotidiana de estas personas: el primero, comenzar a trabajar en el mercado; el segundo, dejar ese trabajo, en coincidencia con el matrimonio o bien con el nacimiento de los hijos (en algunos casos más esto segundo que lo primero).

Con todo, cuando el trabajo productivo es poco cualificado y poco atractivo y la mujer vuelve al hogar, al casarse 0 al tener los hijos, ya no lo hace como en el pasado. La trayectoria de las mujeres jóvenes nos demuestra que puede haber unas opciones conscientes o planificadas, que dejan la puerta abierta a una posterior reincorporación al empleo que, se intenta, sea mejorado a través de mejorar la propia cualificación en el mercado de trabajo... siempre, claro está, que haya empleo.

\section{Las de mediana edad}

Con menor frecuencia que el ama de casa joven, la de mediana edad no ha trabajado en el ámbito productivo durante un largo período o, cuando menos, no lo ha hecho después de casarse. En la totalidad de su trayectoria, por tanto, el trabajo productivo ha sido menos relevante. La trayectoria de vida cotidiana dominante en el ama de casa de media edad es muy tradicional. En su consciencia su vida está marcada por la más absoluta «normalidad»: «lo normal cuando tenías una cierta edad era casarte y dejar de trabajar, si trabajabas... dejarlo y quedarte en casa». También por la más rotunda «inealidad». Con otras palabras, las cosas - en este caso la vida cotidiana - son así porque tienen que ser y lo son a un ritmo que es el esperado y siguiendo unos pasos que son los esperados.

En el grupo anterior, el trabajo productivo es tomado como referente simbólico que podría haber mantenido - de haber tenido ciertas característicasuna vida cotidiana diferente, y que de cualquier modo ha roto ya la imagen tradicional del trabajo reproductivo. En este grupo el trabajo reproductivo es visto desde jóvenes como el rol que se ha de cumplir. Con alguna, en general breve, o sin ninguna experiencia laboral en el mercado, estas mujeres asumen que lo «normal» es que sean amas de casa y que realicen lo mismo que realizaron sus madres.

Pero esta cotidianidad es vivida con una cierta rutina y monotonía. Q uizá es ésta la razón por la cual estas mujeres tienden a recordar con exaltación una etapa de sus vidas, aquélla en la que el tiempo libre y la autonomía que el mismo permitía conferían un mayor entusiasmo o exaltación a la existencia.

L as trayectorias cambian radicalmente si estas mujeres no han dejado de trabajar en el trabajo productivo o se han reincorporado a él después del período de crianza de los hijos. Entonces el trabajo productivo puede pasar a convertirse en la centralidad principal de la vida cotidiana 0 , al menos, en 
la cocentralidad, aunque ello suponga largas jornadas para cubrir ambos ámbitos.

Pero es en esta etapa de la vida en la que las mujeres pueden realizar estrategias, socialmente y frente al grupo familiar, para reivindicar su derecho a la igualdad de oportunidades con su pareja: bien buscando trabajos o profesiones que den satisfacción - porque cuando no es así no se acaba de ver la importancia del trabajo productivo más allá de ser garante de ingresos, y entonces da igual el que sea y en las condiciones que sean - , bien, y al mismo tiempo, buscando un cierto reparto de las tareas domésticas que permita la dedicación al trabajo productivo y al tiempo libre.

El tiempo de libre disposición, disfrutado en familia, en pareja o individualmente, comienza a ser, en la biografía de muchas mujeres, la razón para reivindicar una descarga de las tareas domésticas. En el grado en que esa exigencia es compartida por su pareja, se puede convertir en corrector del desequilibrio de la división tradicional del trabajo.

\section{Las mayores}

La trayectoria de las amas de casa de edad superior a la jubilación - pero que no se han «jubilado» de ser amas de casa - puede estar marcada por dos principales etapas previas: la de dedicación al trabajo doméstico desde el matrimonio o desde que tuvieran los hijos, por tanto una vida de ama de casa que ni siquiera la edad altera; o bien la dedicación al doble trabajo que con la jubilación del productivo queda reducida sólo al doméstico, normalmente ya menos voluminoso que en etapas pasadas.

En cualquiera de las modalidades hay un elemento unificador de toda su tra yectoria: Ia dedicación a la familia. Esa dedicación les ha hecho abandonar el trabajo productivo o bien les ha hecho mantener trabajo productivo y reproductivo. Las referencias al pasado se centran en la familia en torno a la cual aparentemente se ha desarrollado toda la propia trayectoria. Por ello en cierto modo en la vida cotidiana se destacan dos cosas: la primera, casarse y tener hijos - sin dife renciar ambas, puesto que ambas constituyen el bloque básico que es la familia- la segunda, haberse quedado sola por marcha del hogar de unos miembros y muerte de otros; en este caso, la referencia es el desmantelamiento de la familia.

\subsection{Trayectorias de hombres}

En el caso de los hombres, la trayectoria de la centralidad de sus vidas cotidianas está más universalizadamente marcada por la actividad productiva (no nos referimos ahora a las últimas generaciones, en las que la «crisis del empleo» puede estar introduciendo cambios de no poca importancia - aunque sí tendremos en cuenta esto en el apartado siguiente de las transiciones- , sino a las personas que han vivido en el modelo anterior de casi pleno empleo). No es la edad, por tanto, la que introduce los principales cambios en la trayectoria - ciertamente tampoco lo es sólo la edad en las mujeres, aunque sí factores que suelen ir agregados a la edad- , sino otros factores como la clase social, 
el nivel educativo, el tipo de convivencia (la mujer con la que viven); por supuesto, también la edad.

Clase social y nivel educativo

Los niveles educativos al tos, así como la existencia de altos ingresos, han favorecido que muchos hombres hayan ido haciendo un espacio en su tiempo, dominado por la profesión, primero al tiempo libre - tiempo para ellos y sus familias- y luego a la colaboración en el tiempo reproductivo, en general, para que la otra parte también tenga acceso al tiempo libre. Esto último se ha visto favorecido por la posibilidad de salarizar una parte del trabajo doméstico, de manera que ésta - quizá la más penosa - no grave directamente sobre ninguno de los dos miembros de la pareja. Así, los hombres de capas medias y estudios altos se diferencian de aquellos que tienen niveles de estudio bajos y son de categorías bajas, en el hecho de dar espacio a otras centralidades en su propia biografía. C on frecuencia no son las razones culturales sino las económicas las que permiten dar el cambio: es decir, cuando las personas han tenido un trabajo bien pagado, éste ha dejado de ser menos absorbente. Pero también hay ejemplos de lo contrario: la profesión, aun bien pagada, se convierte en eje absoluto de la vida cotidiana.

\section{El entorno familiar}

Podemos ver que en muchos casos los hombres han abierto su propia vida, centrada sobre el trabajo productivo y la profesión, a otros ámbitos de vida cotidiana en manera significativa, cuando han tenido hijos o cuando la propia pareja ha exigido esa apertura, al egando su propio derecho a tener un trabajo fuera del hogar. $\mathrm{H}$ a sido como una especie de «resocialización» que estas personas han tenido cuando las circunstancias de su vida han cambiado profundamente. En buena parte ha dependido de la pareja, puesto que también hay casos en los que el cambio ha sido menos profundo, o ni siquiera se ha dado, en virtud de la «comprensión» de aquélla, que puede aducir que su marido «no sabe hacer nada de lo de casa», «es un desastre en lo doméstico», «lo único que puede hacer es algún tipo de colaboración muy concreta».

\section{Circunstancias biográficas excepcionales}

C ircunstancias excepcionales como la pérdida de los padres, la guerra en al gún caso, el no poder haber realizado estudios, etc., han decantado para ciertos hombres una vida volcada desde niños sobre el trabajo productivo que no ha dejado espacio abierto a ningún otro tipo de actividad ni actitudes o representaciones que no estuvieran ligadas al trabajo productivo. D e la misma manera, otras circunstancias extraordinarias han dado un vuelco a la vida: la muerte de la mujer, el paso a la jubilación, etc., han hecho comprender que en la vida hay otras dimensiones, como las actividades reproductivas o el tiempo libre, que merecen ser consideradas como importantes. El uso del tiempo para sí mismo apa rece en muchos casos como un intento de recuperación del tiempo perdido, de un tiempo unilateralmente dedicado sólo a trabajar asalariadamente. 


\section{La edad}

Ciertamente, también la edad tiene un papel importante. Si comparamos las nuevas generaciones con las generaciones adultas y ancianas podemos comprobar que en las primeras hay una mayor predisposición a una vida cotidiana más policéntrica. Son factores culturales, principalmente, los que influyen: dar importancia al ocio como un aspecto relevante de la propia vida, 0 al cuidado de la propia familia como algo que no es impropio del varón. Pero aparece siempre en el fondo una cierta condición vinculada a la profesión: que ésta pueda ser una condición material adecuada para el cambio, es decir, que sea suficientemente atractiva, segura y bien pagada como para permitir valorar otras cosas sobre una base de seguridad.

\section{Vida cotidiana y cambio: las transiciones}

\subsection{Los tipos nuevos}

La investigación descubre, al menos, tres nuevas formas emergentes de vida cotidiana. En dos de ellas tiene un papel más o menos relevante la exigencia de superar la tradicional división sexual del trabajo y la actuación de las mujeres. Por ello, es de suponer que tienen un cierto carácter de anticipación de lo que será el futuro.

La primera forma la protagoniza el colectivo de mujeres que asumen trabajo productivo y reproductivo al mismo tiempo, pero donde el primero tiene el papel principal en cuanto a valores, aspiraciones, relaciones y representaciones simbólicas, con independencia de las horas que se le dediquen. Ya no es la actividad meramente instrumental, «para ayudar a la familia», que tienen muchas mujeres con doble jornada. Por el contrario, es el trabajo reproductivo el que tiende a convertirse en instrumental: salarizando parte del mismo, ayudándose de electrodomésticos, comidas preparadas, etc. Pero no sólo se trata de un colectivo de mujeres principalmente de clase media 0 al ta y de educación elevada, sino que el tipo de trabajo productivo suele ser cualificado y atractivo. La consecuencia más obvia de esta nueva forma de bicentralidad con decantamiento profesional, es que el tiempo de libre disposición de estas personas queda muy reducido.

En resumen, el nivel educativo de las mujeres y la atracción del trabajo profesional suelen ser los factores que inmediatamente explican esta opción. En el fondo de ellos podemos señal ar la clase social, puesto que sólo determinadas mujeres pueden contar con esos dos elementos. $\mathrm{H}$ emos visto muy claramente en las entrevistas cómo el tipo de empleo puede predisponer a la mujer a volver a su profesión, o no, después de la crianza de los hijos.

La segunda forma capta un colectivo de hombres y mujeres que comparten trabajo reproductivo, con el fin de poder dedicarse, cada uno por su cuenta, al trabajo productivo o bien poder tener más tiempo de libre disposición.

Podríamos hablar, en algún grado, de «modelo de distribución democrática» del conjunto del trabajo (productivo y reproductivo), por más que sea la 
mujer la que suele llevar la iniciativa en el trabajo reproductivo, lo que se explica también porque es la más interesada en que no fracase el esquema de reparto. D e todos modos, hay un triple factor explicativo de esta nueva forma emergente: por un lado, la presión de la propia mujer que aspira a tener tantas oportunidades como el hombre en la sociedad; por otro, la solidaridad del hombre con tales aspiraciones en el terreno del grupo familiar, que es justamente donde esta solidaridad es más rara por la socialización que ha recibido el varón; tercero, la importancia que ambos dan al tiempo libre como tiempo de expresión de otras aspiraciones y deseos que van más allá de la mera recuperación de fuerzas.

También aquí prevalecen personas de clase media y alta, lo que se explica en parte por las connotaciones y las exigencias que la profesión - cualificación de la misma, satisfacción que se encuentra en el trabajo, relación con otras personas, etc. - ejerce sobre cada uno de los miembros de la pareja. Pero también hay personas de clase trabajadora, cuando se dan otros factores de «conscienciación» de la mujer, o de ambos, como el pertenecer a algún tipo de asociación (partido, sindicato, asociación de vecinos, etc.), donde el factor desencadenante del cambio es la relación con otras personas, valores 0 ideas que rompen los esquemas en los que se ha vivido.

En la tercera, la necesidad de disfrutar del tiempo libre parece ser el factor desencadenante. Se nos presenta en diversas modalidades. Puede ser la de quien centraba toda su vida en el trabajo productivo y ahora da mucha importancia al tiempo libre, lo que le lleva no sólo a disminuir el tiempo dedicado al primero, sino también a valorar mucho más el segundo respecto a la propia vida y a la relación con los demás. Puede ser la de quien dedicaba casi todas sus actividades y preocupaciones a lo reproductivo y ahora lo recorta en favor del tiempo libre, no sólo en términos de tiempo, sino también porque cree que viajar, pasear, relacionarse con otros, realizar actividades culturales, etc., es algo muy importante. Puede ser la de quien se ha jubilado ya de su empleo o profesión, o quien ha visto disminuir fuertemente su trabajo reproductivo porque ha disminuido su familia y ahora intenta recuperar el tiempo perdido dedicándose a sí mismo o a sí misma.

En la tercera modalidad, el tiempo de libre disposición ha aumentado notablemente y este simple cambio ha revolucionado la forma de vivir de las personas. Es algo que responde casi a ley de vida, aunque obviamente hay la opción de hacer ese tiempo más activo o más pasivo. En las dos primeras modalidades el cambio responde a que se ha optado por un tipo de vida distinto.

Con frecuencia, en las dos primeras modalidades esta preocupación por el tiempo libre puede ser el primer paso para abrirse a la segunda de las formas de vida descritas, cuando una mujer y un hombre viven juntos y por parte de la primera se da una presión suficiente para que el trabajo reproductivo sea repartido entre ambos. Lo más frecuente es que estas nuevas formas se den más entre las clases medias y altas que entre las bajas, quizá porque ese nuevo uso satisfactorio y atractivo del tiempo libre comporta contar con un cierto nivel económico. 


\subsection{El significado de la transición}

En todas estas formas nuevas, la unidimensionalidad está abriendo paso a la pluridimensionalidad (bicentralidad o tricentralidad), lo que nos permite hablar de vidas cotidianas más ricas.

Las nuevas formas apuntan hacia cambios importantes en la división sexual del trabaj 0 . Los papeles de hombres y mujeres empiezan a ser distintos en la relación habitual de sus vidas cotidianas. En general, la mujer tiene un papel más activo que el hombre en dicho cambio, y ello supone que las experiencias proliferen más en parejas jóvenes, donde ambos pueden estar mucho más abiertos a lo nuevo. En la mujer se comienza a dar una mayor proyección hacia la esfera pública y exterior al hogar que significa el trabajo productivo. En el hombre comienza a darse una concepción de mayor dignidad del trabajo reproductivo.

En el fondo de los cambios hay factores estructurales que deben ser tenidos en cuenta: a favor de ciertos cambios, por ejemplo, las mayores posibilidades de empleo para las mujeres; en contra, que muchos de esos empleos son a jornada parcial y no a jornada completa como los de los hombres. Pero también hay factores biográficos: el que las personas hayan tenido unas o bien otras experiencias de relación, provoca que sean más o menos capaces de dar el paso hacia vidas más compartidas.

Por último, cabe indicar que las nuevas formas inician una transición desde modelos consolidados a lo largo de siglos hacia otros que aún no sabemos cómo serán. Podemos hablar de cambios que se están iniciando. N o sabemos cuál puede ser el destino final de los mismos. 